\title{
Familial Wolf-Hirschhorn syndrome resulting from a cryptic translocation: a clinical and molecular study
}

Evan Reid, Norma Morrison, Lilias Barron, Elizabeth Boyd, Alexander Cooke, David Fielding, J L Tolmie

\begin{abstract}
We present three cousins who have normal karyotypes, despite having clinical features of Wolf-Hirschhorn syndrome. Fluorescence in situ hybridisation techniques confirmed that all three relatives were monosomic for the distal short arm of chromosome 4 and that a cryptic translocation involving chromosomes 4 and 11 was segregating within the family. Segregation analysis indicated that the risk of an affected child being born to a parent carrying the translocation was $15 \%$. Molecular analysis showed that loci D4S111 and D4S115 were not deleted in the proband, thus excluding these loci from the "Wolf-Hirschhorn critical region". Surprisingly, DNA studies also suggested that the translocation breakpoint on chromosome 4 was within the region of a preexisting paracentric inversion.

(f Med Genet 1996;33:197-202)
\end{abstract}

Key words: Wolf-Hirschhorn syndrome; cryptic complex chromosomal rearrangement; critical region.

Wolf-Hirschhorn syndrome is caused by loss of chromosome material from the distal short arm of chromosome $4 .{ }^{1}$ Characteristic clinical features are severe growth retardation, mental handicap, microcephaly, ocular colobomata, cleft lip and palate, congenital cardiac defects, and genital abnormalities. In $90 \%$ of cases the chromosome 4 deletion arises as a de novo event, whereas in the remainder it is derived from a familial balanced translocation. ${ }^{2}$ Several cases have been described where Wolf-Hirschhorn syndrome was caused by a chromosome 4 abnormality detectable solely by molecular genetic techniques. ${ }^{3-7}$

We describe a large family where the karyotypically normal proband had clinical features suggestive of Wolf-Hirschhorn syndrome. Two distant relatives were affected by multiple congenital abnormalities and we suspected that a translocation involving chromosome 4 was segregating within the family. Molecular genetic in situ hybridisation techniques were required to show the presence of a submicroscopic, reciprocal translocation between chromosomes 4 and 11 . Unexpectedly, DNA studies suggested that the translocation breakpoint on chromosome 4 was within the region of a pre-existing paracentric inversion.

Molecular genetic studies have delineated a roughly $2 \mathrm{Mb}$ long "Wolf-Hirschhorn critical region", the shortest area of overlap of deletions causing Wolf-Hirschhorn syndrome, between loci D4S43 and D4S90. ${ }^{5}$ DNA studies in our proband and her parents allowed us to shorten the critical region by excluding loci D4S111 and D4S 115 from it.

\section{Subjects and methods}

CASE 1 (FIG 1, V.9 AND FIG 2): PROBAND

After an uncomplicated pregnancy, the proband was born at term by forceps delivery for fetal distress, weighing $3320 \mathrm{~g}$. She was noted to have a cleft soft palate, a high nasal root, low set, posteriorly rotated ears, a well demarcated philtrum, cupid's bow mouth, and microcephaly. Unusual prominence of the glabella and nasal root led to a clinical suspicion of Wolf-Hirschhorn syndrome. Her early postnatal course was notable for failure to thrive and poor feeding. A ventricular septal defect and mild pulmonary valve stenosis were diagnosed in infancy. She developed epilepsy at approximately 6 months of age. Initially, this took the form of partial motor seizures, but later she developed generalised tonic-clonic seizures. She had bilateral secretory otitis media at 18 months. Subsequent development has been characterised by severe growth retardation (below the 10th centiles for height, weight, and head circumference) and intellectual disability.

CASES 2 (IV·8) AND 3 (IV·10) (FIG 3)

This brother and sister, aged 31 years and 25 years respectively, were second cousins once removed of case 1 . They had normal birth weights at term and a similar pattern of abnormalities (severe cognitive disability, microcephaly, seizures, cleft palate, postnatal growth retardation) to the proband. Despite having normal birth weights, these sibs were thought to have an underlying diagnosis of Seckel syndrome.

\section{CYTOGENETIC ANALYSIS}

Using standard cytogenetic procedures, metaphase chromosome spreads were obtained from the proband and her parents. Repeated conventional and high resolution study of Giemsa stained preparations showed normal karyotypes with no detectable abnormality of chromosome $4 \mathrm{p}$. 


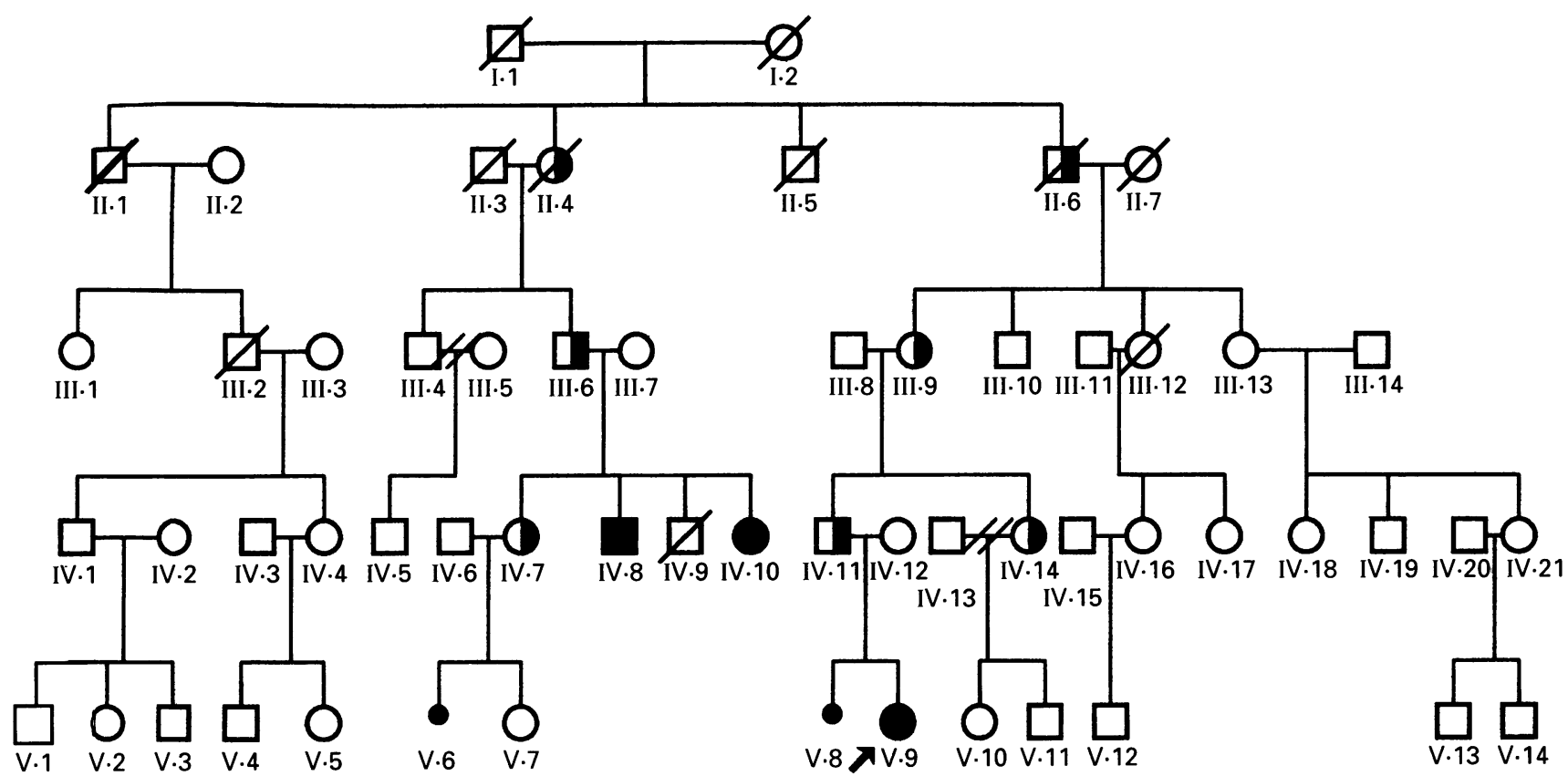

Figure 1 Pedigree of family. Solid symbols represent affected subjects, half solid symbols represent carriers of the balanced translocation.

IN SITU HYBRIDISATION

pK082, a $5.5 \mathrm{~kb}$ subclone of G8 in pBR328 was used as a probe for region $4 \mathrm{p} 16.3$ and phins 311 , an $8.6 \mathrm{~kb}$ DNA clone in pBR322, for $11 \mathrm{p} 15.5 .{ }^{9}$ Both probes are available from the American Type Culture Collection. Telomere specific probes for $4 p$ (in combination with a chromosome 4 centromere probe) and $11 \mathrm{p}$ were purchased from Oncor (Gaithersburg, MD).

The probes were used for either in situ hybridisation with enzymatic detection according to Garson et $a l^{10}$ (pK082 hybridisations to IV·11, IV·12, IV·16, IV·17, V·9) or for fluorescence in situ hybridisation (FISH), as described by Pinkel et $a l^{11}$ with modifications detailed by Carter et al. ${ }^{12}$ Fluorescent images were captured and stored using the Smartcapture digital imaging system (Digital Scientific, Cambridge, UK). Pseudocoloured images were produced in monochrome for publication.

For both enzymatic and fluorescence detection procedures involving $\mathrm{pK} 082$ and phins

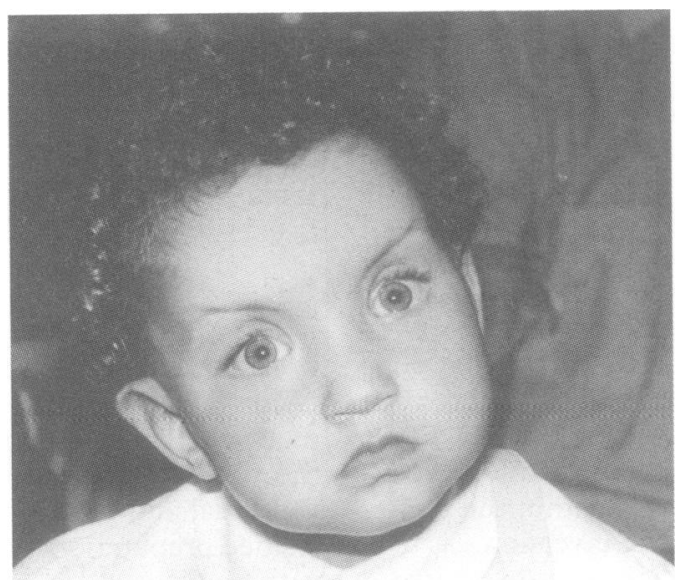

Figure 2 Case 1, aged 2 years 4 months
311, signals visualised on the posthybridisation metaphases were marked on the photographs of prehybridisation, banded metaphases. The distribution of hybridisation signals in chromosome spreads was analysed statistically using the $\chi^{2}$ test.

Metaphases were assessed for hybridisation of telomeric $11 \mathrm{p}$ and $4 \mathrm{p}$ probes to chromosomes 4 and 11 after identification of these chromosomes by DAPI (4,6 diamidino-2phenylindole) band enhancement using Smartcapture software.

DNA ANALYSIS

DNA was extracted by standard techniques from the blood of the proband and her parents. Polymerase chain reaction amplifications were carried out as previously described for the variable number tandem repeat sequences at loci D4S111, D4S114, D4S115, and D4S43 and the trinucleotide repeat sequence within the Huntington's gene. ${ }^{13-15}$ Reaction product was electrophoresed on a $2 \%$ agarose gel or a $6 \%$ acrylamide gel, depending on its size.

\section{Results}

Segregation analysis was carried out according to the method described by Gardner and Sutherland. ${ }^{16}$ Excluding the proband and her direct antecedents, 13 offspring were born to carrier parents and two children were affected by Wolf-Hirschhorn syndrome. The risk of a carrier having an affected child is therefore $15 \%$, with a standard error of $10 \%$.

IN SITU HYBRIDISATION

The proband had a signal peak on only one chromosome 4 following hybridisation to pK082. This confirmed the clinical suspicion of Wolf-Hirschhorn syndrome. The proband's 

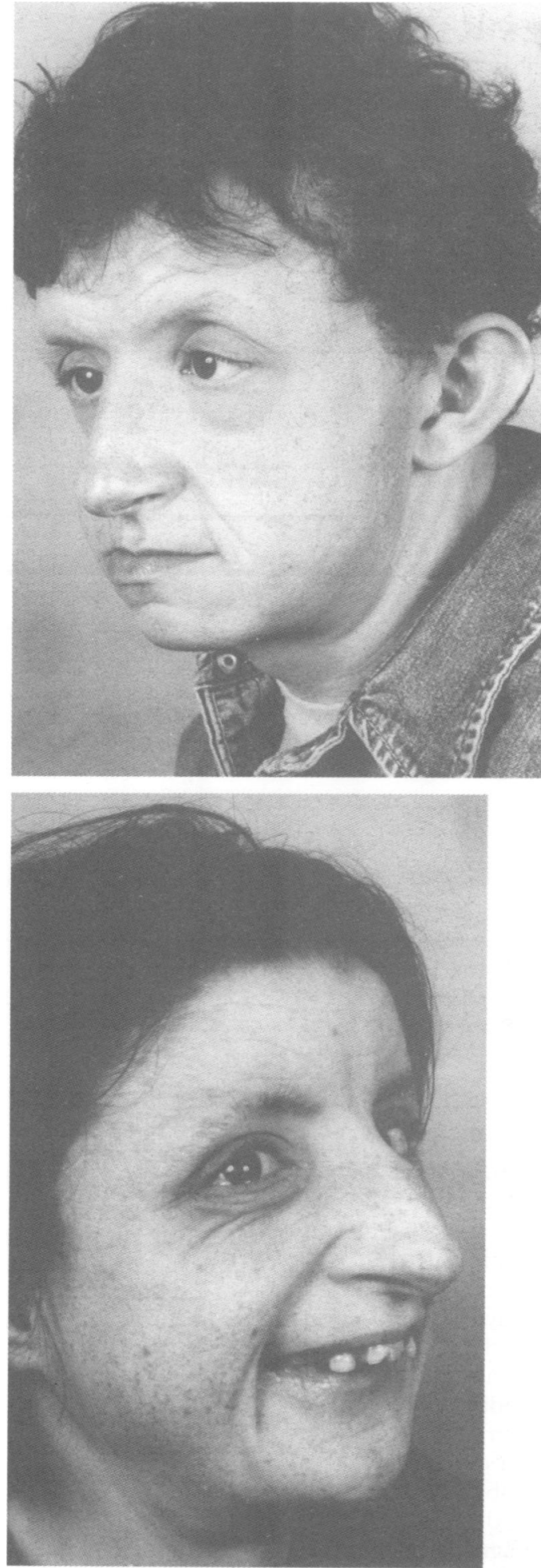

Figure 3 (Top) Case 2. (Bottom) Case 3.

father (IV·11) had a signal peak on chromosome 4 and chromosome 11 with pK082 and subsequent hybridisation with probe phins 311 showed both the proband and her father had signal peaks on chromosome 4 and chromosome 11. These results, in conjunction with the chromosomal distribution of signal on individual metaphases (fig 4), indicate that the father was a carrier of a balanced reciprocal translocation involving the short arms of chromosomes 4 and $11(\mathrm{t}(4 ; 11)(\mathrm{p} 16.3 ; \mathrm{p} 15.5))$ and that the proband had the unbalanced karyotype

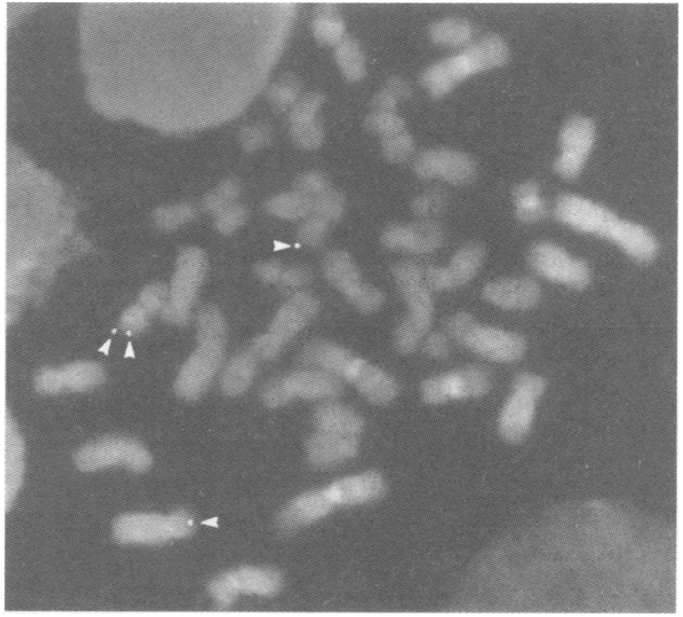

Figure 4 Metaphase spread prepared from proband showing FISH with probe phins 311 (target 11p15.5). Signal (arrowheads) is present on one chromosome 4 and both chromosomes 11 .

$46, \mathrm{XX},-4,+\operatorname{der}(4) \mathrm{t}(4 ; 11)(\mathrm{p} 16.3 ; \mathrm{p} 15.5) \mathrm{pat}$. IV 8 and IV 10 (cases 2 and 3 ) had similar results to the proband following hybridisation to $\mathrm{pK} 082$ and phins 311 . Examination of other family members showed four phenotypically normal subjects (III·6, IV·7, IV·11, IV·14) with signal peaks on chromosomes 4 and 11 following hybridisation to $\mathrm{pK} 082$, indicating that they were carriers of the balanced translocation. These findings were confirmed by the probe phins 311, which also showed that these four people had signal peaks on chromosomes 4 and 11. III. 6 had signal on one chromosome 4 and one chromosome 11 with telomere specific probes for both chromosome $11 \mathrm{p}$ and $4 \mathrm{p}$, confirming the reciprocal nature of the translocation involving the two chromosomes.

Three normal subjects (IV·12, IV 16, IV 17 ) had signal peaks on chromosome 4 only with probe $\mathrm{pK} 082$, indicating that they did not carry the translocation. A further five cases (III-10, III $\cdot 13$, IV 1 , IV 4 , IV $\cdot 21$ ) had only a chromosome 4 signal peak following hybridisation with pK082 and only a chromosome 11 signal peak following hybridisation with phins 311 , again indicating that they did not carry the translocation. One carrier of the balanced translocation (IV-7) became pregnant during the course of our investigations. Amniocentesis was performed at 14 weeks of gestation and FISH with probes pK082 and phins 311 was performed on cultured amniocytes. The fetus had a normal female chromosome constitution (46, $\mathrm{XX}$ ), without molecular cytogenetic evidence of a $\mathrm{t}(4 ; 11)$ translocation. A phenotypically normal female infant weighing $3490 \mathrm{~g}$ was born at term.

Results of molecular genetic analysis on proband and parents

\begin{tabular}{|c|c|c|c|}
\hline \multirow[t]{2}{*}{ Locus } & Proband & Father & Mother \\
\hline & Allele & Allele & Allele \\
\hline $\mathrm{HD}$ & 1 & $3 / 3$ & $1 / 2$ \\
\hline D4S43 & 3 & $1 / 2$ & $3 / 4$ \\
\hline $\begin{array}{l}\text { D4S114 } \\
\text { D4S115 }\end{array}$ & Uninformative & $1 / 2$ & $3 / 4$ \\
\hline D4S111 & $1 / 2$ & $1 / 2$ & $\begin{array}{l}3 / 4 \\
1 / 2\end{array}$ \\
\hline
\end{tabular}


16.1

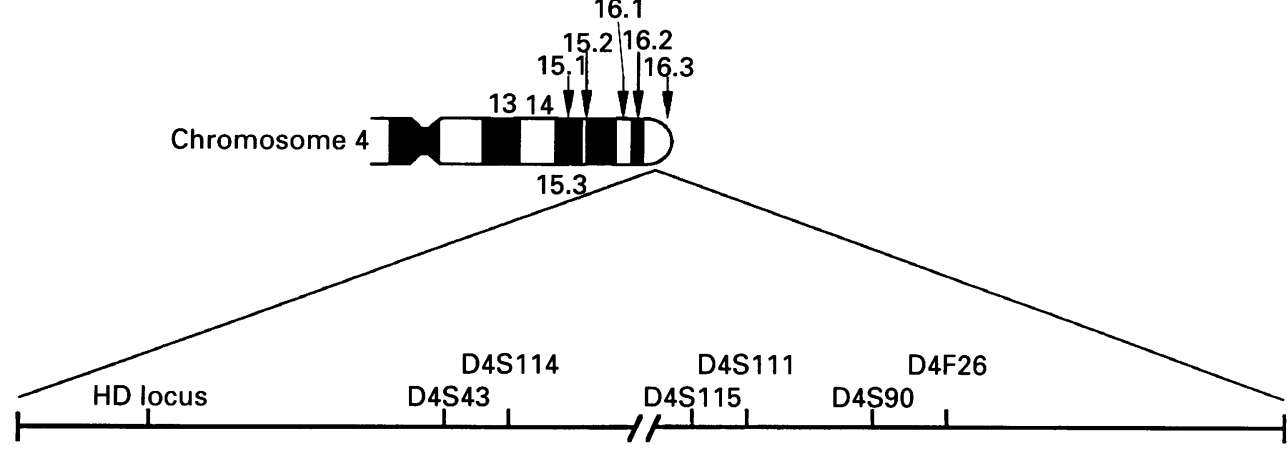

Figure 5 Schematic physical map of $4 p 16.3$ (revised from fohnson et ap') showing relative positions of selected loci. Previously reported deletions have been marked with bold lines: (a) our proband, (b) Fohnson et al, ${ }^{5}$ (c) Gandelman et $a l l^{17}(d)$ Alther et al,$^{18}(e)$ Gandelman et al. ${ }^{17}$ The dotted lines in $a$ and $b$ signify that the exact proximal and distal boundaries of the deletions are not known. Cases $a, b, c$, and d have Wolf-Hirschhorn syndrome phenotypes, while e does not. HD represents the Huntington's disease locus.

DNA ANALYSIS

The results of the polymerase chain reaction amplifications are shown in the table. The proband was hemizygous for a region between the Huntington's disease locus and D4S43, but heterozygous at the more telomeric loci D4S111 and D4S115 (fig 5).

\section{Discussion}

Normal cytogenetic results are an indication for molecular genetic investigation in patients who have phenotypic features strongly suggestive of an underlying chromosome imbalance. ${ }^{19}$ Submicroscopic deletions or translocations have been detected using DNA probes with Southern blot hybridisation, polymerase chain reaction based polymorphisms, and fluorescence in situ hybridisation in a variety of conditions, ${ }^{2021}$ including sporadic and familial ( $\mathrm{sib}$ or first cousin) cases of WolfHirschhorn syndrome. ${ }^{3-7}$ In our family, it was initially thought that the proband had the same autosomal recessive disorder (Seckel syndrome) which had been diagnosed in distantly related male and female sibs. However, from the appearance of the proband and inspection of the family pedigree, we suspected that a translocation involving the short arm of chromosome 4 was segregating within the family. No abnormality of chromosome 4 could be visualised using high resolution chromosome banding but molecular genetic in situ hybridisation techniques successfully detected a submicroscopic translocation between chromosomes 4 and 11. The clinical diagnosis of Wolf-Hirschhorn syndrome was confirmed in the proband and her cousins by showing that they have the translocation in an unbalanced form and are monosomic for a segment of distal 4 p. Four phenotypically normal subjects have the cryptic $t(4 ; 11)$ translocation in a balanced form and eight subjects were confirmed as having a normal karyotype. Segregation analysis in this extensive kindred showed that the risk that a carrier of the balanced translocation might have an affected liveborn child was $15 \%$, with a standard error of $10 \%$. This is in exact agreement with the results of segregation analysis carried out on a large family with WolfHirschhorn syndrome resulting from a cytogenetically visible, reciprocal translocation. ${ }^{2}$

We successfully carried out prenatal diagnosis in a carrier of the balanced $t(4 ; 11)$ translocation, using fluorescence in situ hybridisation on cultured amniocytes. In a family with Wolf-Hirschhorn syndrome caused by submicroscopic translocation, Alther et al ${ }^{6}$ used DNA probes with Southern blot hybridisation to show that DNA from a cultured chorionic villus sample was disomic for the short arm of chromosome 4. Goodship et $a l^{3}$ used the same techniques in combination with fluorescence in situ hybridisation for prenatal diagnosis in a similar family, again using cultured chorionic villus cells. They suggested that in families with a subtle translocation, fluorescence in situ hybridisation should be the technique of choice for prenatal diagnosis since it allows identification of all unbalanced products, it can distinguish between a normal karyotype and a balanced carrier, and its accuracy is not affected by recombination events. Pettenati et $a l^{22}$ detected an unbalanced chromosome abnormality of the type which causes cri du chat syndrome by using fluorescence in situ hybridisation on uncultured amniocytes. Our result adds to the emerging body of evidence that fluorescence in situ hybridisation is a reliable technique for prenatal detection of cryptic translocations. 
A

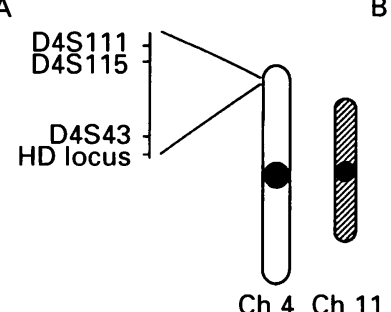

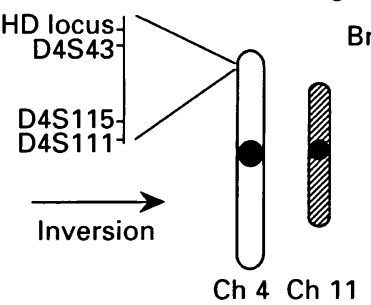

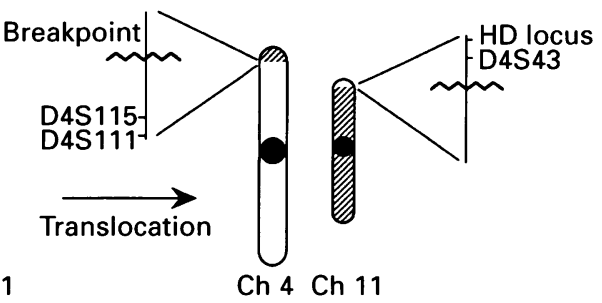

D

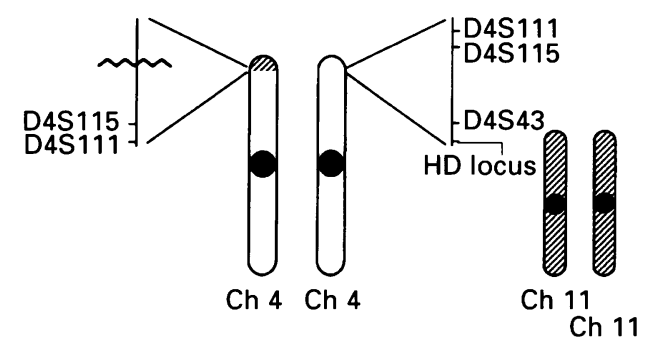

Figure 6 Schematic diagram of the mechanisms by which the derivative chromosome 4 may have arisen. (A) Normal chromosomes 4 and 11, with a schema of the relative physical order of chromosome 4 marker loci shown left; (B) a small inversion occurs, reversing the order of the marker loci; (C) a reciprocal translocation involving chromosomes 4 and 11 occurs; the breakpoint on chromosome 4 is within the pre-existing inversion, between loci D4S43 and D4S115; (D) the translocation in the unbalanced form in the proband. The proband is heterozygous at loci D4S111 and D4S115, but hemizygous at D4S43 and the Huntington's disease locus (HD).

An unexpected finding in our family was that a novel chromosomal rearrangement involving the translocated chromosome 4 has occurred. The PCR based molecular results in the proband show that she is hemizygous for a region between the Huntington locus and locus D4S43. However, she is heterozygous at two loci, D4S111 and D4S115, located telomeric to D4S43. The in situ hybridisation results on III 6 clearly indicate that the telomeric regions of the short arms of chromosome 4 and 11 are reciprocally exchanged in carriers of the balanced translocation. The PCR based molecular data therefore suggest that the breakpoint on the translocated chromosome 4 was within the region of a pre-existing paracentric inversion (fig 6). Complex chromosomal rearrangements which are entirely submicroscopic have not previously been described, but study of light microscopically visible complex rearrangements with molecular techniques has shown unsuspected cryptic abnormalities. ${ }^{23}$ Light microscopically visible translocations are seldom intensively investigated by molecular techniques and it may be that cryptic complex chromosomal rearrangements are more common than currently suspected.

Analysis of DNA from patients with deletions of distal chromosome $4 \mathrm{p}$ has allowed the definition of a Wolf-Hirschhorn "critical region", the smallest area of overlap of all the deletions causing Wolf-Hirschhorn syndrome. ${ }^{51724} \mathrm{Gan}$ delman et $a l^{17}$ defined the critical region as being a $2 \cdot 2 \mathrm{Mb}$ long section in $4 \mathrm{p} 16.3$ between loci D4S43 and D4F26. Johnson et al shortened the region at its telomeric end by excluding locus D4F26. Our proband is hemizygous for the PCR based markers at the
Huntington locus and locus D4S43. She is heterozygous at loci D4S111 and D4S115, excluding these loci from the telomeric end of the critical region and suggesting that it lies between loci D4S43 and D4S115 (fig 5).

Our modification of the critical region relies on the proband having classical clinical features of Wolf-Hirschhorn syndrome, including growth and mental retardation, microcephaly, seizures, congenital heart disease, and cleft palate. Ocular colobamata and genital abnormalities were absent. Perhaps the single most useful diagnostic feature of Wolf-Hirschhorn syndrome is the facial "gestalt" and it was recognition of this in the proband which was the impetus for the molecular cytogenetic studies which confirmed the diagnosis. She had no specific features of trisomy $11 \mathrm{p},{ }^{25}$ which might have complicated the clinical picture.

A preliminary phenotypic map of chromosome $4 \mathrm{p} 16$ has been prepared recently. ${ }^{26}$ The clinical and molecular findings in our proband are compatible with this phenotypic map, with two exceptions: firstly, as discussed above, the definition of the extent of the Wolf-Hirschhorn critical region, and, secondly, our data suggest that D4S111 and D4S115 can be excluded from the region of deletions which cause a prominent glabella.

It is not yet known which genes must be deleted to cause the Wolf-Hirschhorn phenotype. It has been suggested that a zinc finger gene mapping to locus D4S90 might be a candidate gene. ${ }^{27}$ Both our results and the results of Johnson et at suggest that this locus is outside the Wolf-Hirschhorn critical region and tend to exclude the gene from playing a significant pathogenetic role. 
In summary, this family reinforces the fact that submicroscopic chromosomal abnormalities are an important, underdiagnosed cause of genetic disease. Clinical suspicion and simple inspection of the family tree are as crucial to their detection as sophisticated molecular cytogenetic techniques.

Probe pK082 was the generous gift of Dr James F Gusella. We thank Jean Hislop for illustrations, Professor Robin Winter fo his suggestion, made in 1988 , that the proband had features of Wolf-Hirschhorn syndrome, and many members of the extended family for their patience and cooperation.

1 Wolf $\mathrm{U}$, Reinwein $\mathrm{H}$, Porsch $\mathrm{R}$, et al. Defizienz an den kurzen Armen eines Chromosoms $\mathrm{nr} 4$. Humangenetik $1965 ; 1: 397-413$.

2 Tranebjaerg L, Peterson A, Hove K, et al. Clinical and cytogenetic studies in a large $(4: 8)$ translocation family with pre-and postnatal Wolf syndrome. Ann Genet (Paris) 1984;27:224-9.

3 Goodship J, Curtis A, Cross I, et al. A submicroscopic translocation $\mathrm{t}(4 ; 10)$, responsible for recurrent Wolf-Hirschhorn syndrome identified by allele loss and fluorescent in situ hybridisation. 7 Med Genet 1992;29:451-4.

4 Hagg MM, Lunt B, Berry R, et al. Detection of cryptic translocation $4 \mathrm{p}$ and $11 \mathrm{p}$ common to 2 unrelated families using fluorescent in situ hybridisation (FISH) techniques. Am $\mathcal{f}$ Hum Genet 1992;51:A80

5 Johnson VP, Alther MR, Blake JM, et al. FISH detection of Wolf-Hirschhorn syndrome: exclusion of D4F26 as critical site. Am 7 Med Genet 1994;52:70-4

6 Alther MR, Bengtsson U, Elder FFB, et al. Molecular confirmation of Wolf-Hirschhorn syndrome with a subtle translocation of chromosome 4. Am f Hum Genet 1991; 49:1235-42.

7 Fagan K, Colley P, Partington M. A practical application of fluorescent in situ hybridisation to the Wolf-Hirschhorn syndrome. Pediatrics 1994;93:826-7.

8 MacDonald ME, Anderson MA, Gilliam TC, et al. A somatic cell hybrid panel for localising DNA segments nea the Huntington's disease gene. Genomics 1987;1:29-34.

9 Xiang K, Karam JH, Bell GI. Bam HI RFLP at the insulin growth factor II (IGF2) locus on chromosome 11. Nucleic Acids Res 1987;15:7655.

10 Garson JA, Van den Berghe JA, Kemshead JT. Novel nonisotopic in situ hybridisation technique detects small $(1 \mathrm{~kb})$ unique sequences in routinely G-banded human chromosomes: fine mapping of $\mathrm{N}$-myc and beta-NGF genes. Nucleic Acids Res 1987;15:4761-70.

11 Pinkel D, Straume T, Gray JW. Cytogenetic analysis using 作 Proc Natl Acad Sci USA 1986;83:2934-8.
12 Carter NP, Ferguson-Smith MA, Perryman MT, et al. Reverse chromosome painting: a method for rapid analysis of aberrant chromosomes in clinical cytogenetics. $7 \mathrm{Med}$ Genet 1992;29:299-307.

13 Allitto BA, McClatchey AI, Barnes G, et al. Assay by polymerase chain reaction (PCR) of multi-allele polymorphisms in the Huntington's disease region of chromosome 4. Mol Cell Probes 1992;6:513-20.

14 Francomano CA, Ortiz de Luna RI, Hefferon TW, et al. Localization of the achondroplasia gene to the distal $2.5 \mathrm{Mb}$ of human chromosome $4 \mathrm{p}$. Hum Mol Genet 1994; 3:787-92.

15 Warner JP, Barron LH, Brock DJH. A new polymerase chain reaction (PCR) assay for the trinucleotide repeat that is unstable and expanded on Huntington's disease chromosomes. Mol Cell Probes 1993;7:235-9.

16 Gardner RJM, Sutherland GR. Chromosome abnormalities and genetic counselling. Oxford: Oxford University Press, 1989:22-5.

17 Gandelman KY, Ginson L, Meyn MS, et al. Molecular definition of the smallest region of deletion overlap in the Wolf-Hirschhorn syndrome. Am 7 Hum Genet 1992;51: $571-8$

18 Alther MR, Gusella JF, Wasmuth JJ, et al. Molecular detection of a $4 \mathrm{p}$ deletion using PCR based polymorphisms: a technique for the rapid detection of the Wolf Hirschhorn a technique for the rapid detection of the Wolf Hir

19 Flint J, Wilkie AOM, Buckle VJ, et al. The detection of subtelomeric chromosomal rearrangements in idiopathic subtelomeric chromosomal rearrangements in id
mental retardation. Nature Genet 1995;9:132-9.

20 Lamb J, Harris PC, Lindenbaum RH, et al. Detection of breakpoints in submicroscopic chromosomal translocation, illustrating an important mechanism for genetic disease. Lancet 1989;ii:819-23.

21 Bonthron DT, Smith SJL, Fantes J, et al. De novo microdeletion on an inherited Robertsonian translocation chromosome: a cause for dysmorphism in the apparently balanced translocation carrier. Am f Hum Genet 1993;53: 629-37.

22 Pettenati MJ, Hayworth R, Cox K, et al. Prenatal detection of cri du chat syndrome on uncultured amniocytes using fluorescence in situ hybridisation (FISH). Clin Genet 1994; 45:17-20.

23 Batista DAS, Pai GS, Stetten G. Molecular analysis of a complex chromosomal rearrangement and a review of complex chromosomal rearrangement and a revil

24 Estabrooks LL, Lamb AN, Aylesworth AS, et al. Molecular characterisation of chromosome $4 \mathrm{p}$ deletions resulting in Wolf-Hirschhorn syndrome. F Med Genet 1994;31:103-7.

25 Schinzel A. Catalogue of unbalanced chromosome aberrations in man. Berlin: de Gruyter, 1984:434-7.

26 Estabrooks LL, Rao KW, Driscoll DA, et al. Preliminary phenotypic map at chromosome 4 p16 based on $4 \mathrm{p}$ deletions. Am ₹ Med Genet 1995;57:581-6.

27 Tommerup N, Aagaard L, Lund CL, et al. A zinc finger gene ZNF141 mapping at $4 \mathrm{p} 16.3 / \mathrm{D} 4 \mathrm{~S} 90$ is a candidate for the Wolf-Hirschhorn (4p-) syndrome. Hum Mol Genet 1993;2:1571-5. 